\title{
The Advantage of Network Multimedia in Physical Education Teaching Compared with Traditional Teaching
}

\author{
Huang $\mathrm{Qi}^{1,{ }^{*}}$ and Xiaowei $\mathrm{Zou}^{2}$ \\ ${ }^{1}$ Department of Physical Education, Heilongjiang Bayi Agricultural Universtiy, Daqing 163319, Heilongjiang, China; \\ ${ }^{2}$ English Department, College of Humanities and Social Sciences, Heilongjiang Bayi Agricultural University, Daqing, \\ Heilongjiang Province, 163319, China
}

\begin{abstract}
The use of multimedia technology has improved the sports skills as well as the quality of thinking, and has played a significant role in the enhancement of the teaching principles. Use of multimedia technology optimizes classroom teaching, changing the physical education teaching from concept to form, in turn promoting quality education. This article is based on the related issues of multimedia applied to physical education teaching exploration, mainly studying the meanings and characteristics, using the principles in physical education teaching.. Therefore, multimedia courseware is produced based on the pattern which explores the sports technology courses teaching and the production rules and methods of multimedia courseware. Through application in teaching, five advantages of using multimedia courseware teaching are explored suggesting that multimedia courseware teaching should have three different levels of software and hardware conditions.
\end{abstract}

Keywords: Application methods, multimedia technology, sports technology teaching, traditional teaching.

\section{INTRODUCTION}

With the rapid development of science and technology, knowledge economy has become the main characteristic of today's society. Therefore, how to cultivate students to become qualified and talented individuals has become an important subject for the education workers. Sports are an important part of quality-oriented education and are also important for a comprehensive and balanced development of an individual. For promoting quality education today, with the wide application of computer multimedia technology, the traditional sports teaching method is being more and more seriously challenged, exposing disadvantages of traditional PE teaching. As a result, the complementary role of multimedia courseware in physical education teaching has become more important [1-6]. College sports multimedia network teaching platform is based on the development of the internet as a collection system for colleges and universities sports teaching, for not only democracy, personalized sports knowledge learning and as communication platform, but also for daily physical education teaching in colleges and universities.

In the $21^{\text {st }}$ century, improving education and cultivating new talents with strong competitiveness and high quality became common concerns for all countries in the world. School is a platform that cultivatestalent base, the center of which is teaching, and teaching reform is the key to cultivate talents. The reformulation of the teaching methods and

*Address correspondence to these authors at the Department of Physical Education, Heilongjiang Bayi Agricultural Universtiy, Daqing 163319, Heilongjiang, China; E-mail: Huangqibynd@163.com means is an important part of the teaching reform. Traditional physical education teaching, and the model of technology are mainly "explanation, demonstration and practice", with theory mainly a "blackboard with a mouth ".This so far has not kept up with the situation of the teaching reform; therefore the need to use modern teaching means has gained importance. Computer Assisted Instruction as the $20^{\text {th }}$ century's most notable achievements in education and the crystallization of human wisdom has become a main part of education science and the modern education technology, to provide the strategic means for scientific research and the directions for innovation in teaching. This topic attempts to introduce multimedia network technology in physical education teaching, through the design of multimedia network courseware and its application in teaching, in order to explore the method for its advantages and characteristics and apply it in the teaching of sports, for the improvement of teaching quality, such that the sports talents can meet the demand of the $21^{\text {st }}$ century [7-10].

\section{THE BASIC STRUCTURE OF THE NETWORK MULTIMEDIA TEACHING PLATFORM}

The multimedia network teaching platform uses the latest $\mathrm{B} / \mathrm{S}$ (browser/server) structure, as shown in Fig. (1). The characteristics of the structure are as follows: the client application environment for the standardized general Web browser enabling all the applications to be stored on a Web server, which can be directly downloaded when needed; more easy to manage and maintain, as the client without any special software, only needs to update the server software when in need to upgrade network applications; the structure has good expansibility, openness, B/S structure with a stan- 


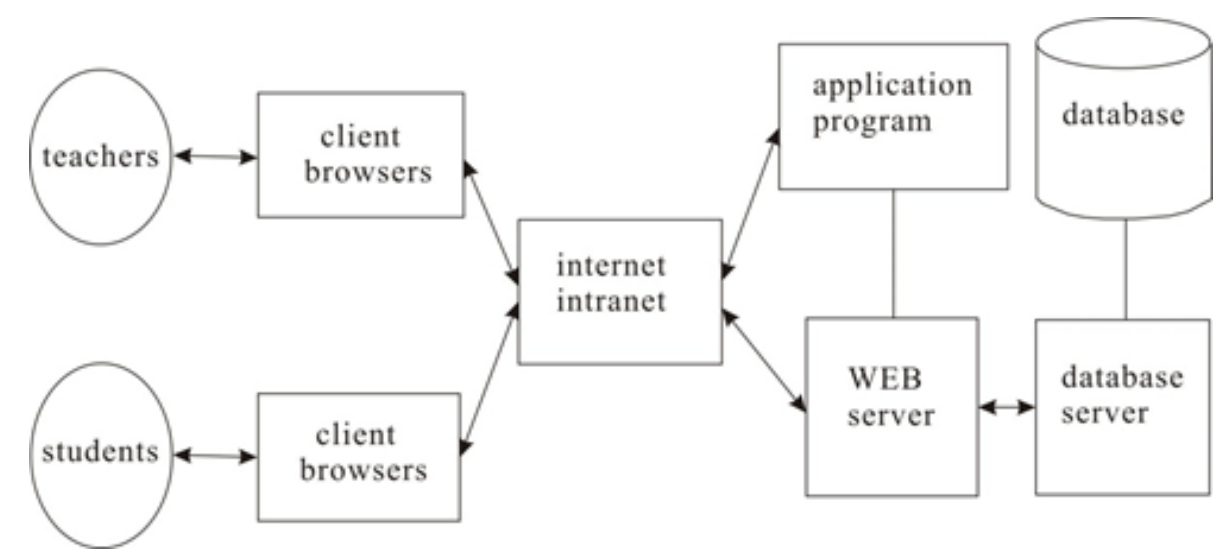

Fig. (1). Multimedia network teaching platform structure.

Table 1. The comparison between tradition and internet teaching model.

\begin{tabular}{|c|c|c|}
\hline Teaching Model & Relation Between Teachers and Students & Corresponding Relation \\
\hline \hline tradition & direct, face to face & one-to-many \\
\hline Internet & Indirect & many-to-many \\
\hline
\end{tabular}

dard TCP/IP communication protocol, and the school according to their own development needs can expand the system at any time [11].

Working principle provides teachers and students access to the multimedia network teaching platform through the browser, as students can use personal computer equipment connected to the server via a browser, carry on the related sports in teaching contents and learning resource information query, and have timely communication between teachers and students Multimedia network teaching platform of management and college sports teachers can update content stored in the server through the browser and the maintenance, and at the same time the latest sports teaching resource information uploaded to the server side, can be achieved by an online question of the student, which can provide sports guidance to students. Server consists of a Web server and database server. With a Web server to store all kinds of application modules in the system, the application functions of customer are completed, when the user's request is received by the client and translated into a database request after interaction with the database server. This interaction then results in the form of a Web page which is to be downloaded from the browser, and the users can request the observed results. Database server storage required by the system database and its management software, is according to the request from the Web server for database operation, and the results are transmitted to the Web server.

The characteristic of the multimedia network teaching is one of real-time traffic information technology. Multimedia network teaching platform has a very powerful information resources sharing. Timely communication between teachers and students is conducive to maintaining smooth physical education teaching. In the traditional sports teaching in colleges and universities, the teaching in class is carried out on a large number of students, which makes the communication between teachers and students restricted to a certain degree.
However, through the multimedia network teaching platform, online interaction between the teacher and students is implemented. . This may help in improving the teaching interaction between the two sides, in turn improving the teaching level and teaching efficiency. Table $\mathbf{1}$ shows the communication between teachers and students and the traditional sports teaching mode based on the comparison of multimedia network teaching platform mode.

\section{DESIGN PROCESS OF NETWORK MULTIMEDIA COURSEWARE}

\subsection{Courseware Overall Design}

Sports technology of multimedia network courseware production pattern works on the basis of computer aided teaching and the basic principle of software development. According to the professional characteristics of sports technology teaching, the combination of the courseware development sets out a suitable medium for multimedia network courseware of sports technology teaching pattern, as shown in Fig. (2).

Through the courseware application in teaching and students' self-study process, providing students with a vivid and intuitive learning process is a combination of interactive learning environment, which makes full use of computer graphics, image, animation, sound, video, and other functions, so that students establish the correct technical concepts, mastering the project technology, and master in theory task, in all the stages of technical specifications, technical essentials, teaching methods and means, and gain recognition of the common error action. In addition, through the selection of resources for study and design of the courseware of quizzes and tests, the students' learning efficiencies and learning interests are improved, broadening the students' knowledge and enabling them to master the knowledge of the project. The developed courseware should be based on 


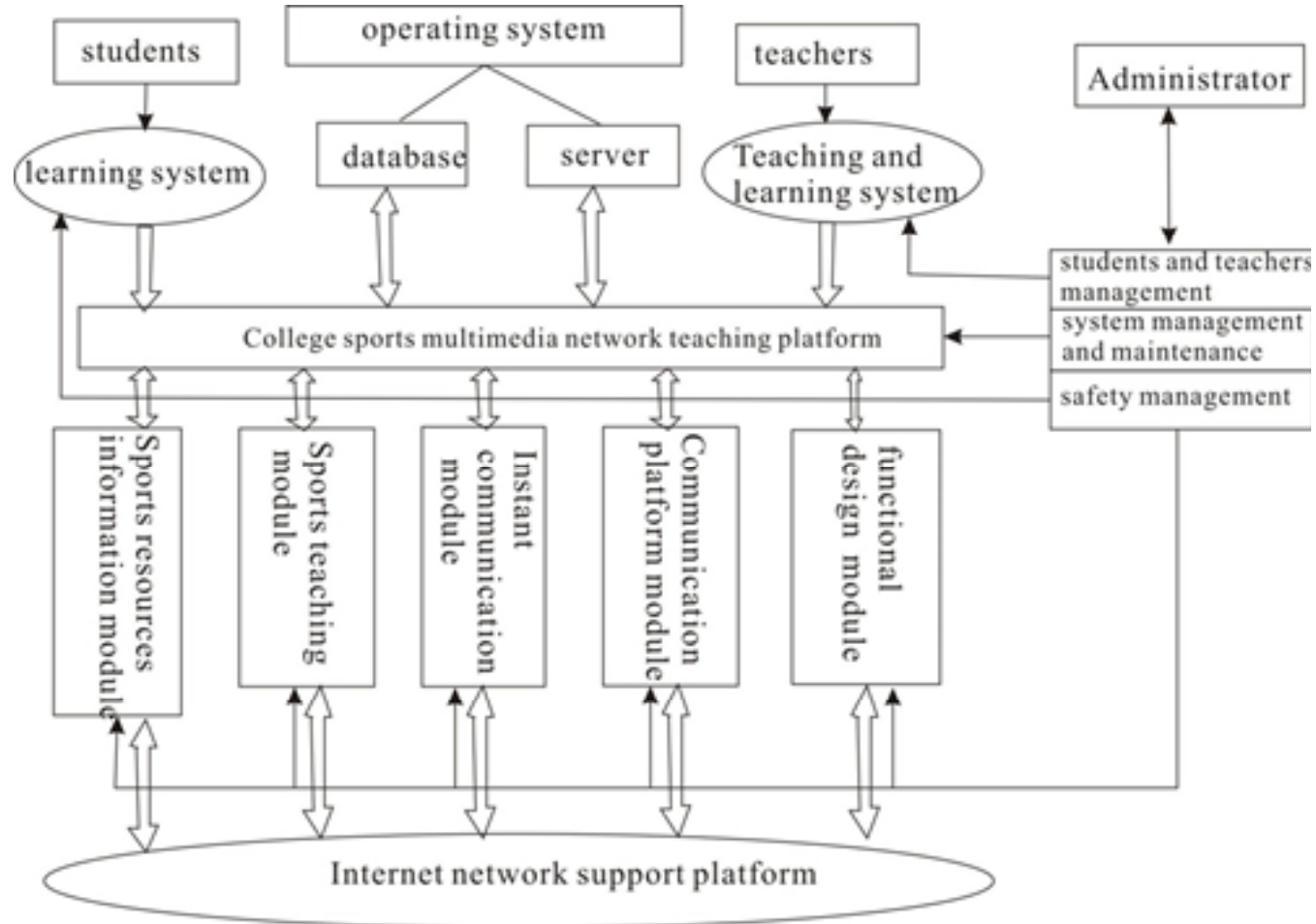

Fig. (2). Support structure of college sports multimedia network teaching platform.

the sports teaching outline, based on the project of the latest teaching material to write about the teaching content, serving as the project review for teachers, and holding a colloquium, and after numerous modifications, courseware teaching content is determined.

The choice of media is more convenient, flexible and economic as the computer can voice, image, video, text process, etc. However, in order to prevent any misuse of the media, while choosing media, a couple of five principles are followed: (1) the objective principles; (2) fewer but better principles; (3) optimization decision-making principles; (4) moderate principle; (5) the highest benefit principle. In the media choices, some kinds of media should not be randomly chosen; rather several media are put together following certain principles: objective principles; Multi-sensory matching principle; big information principle; Interaction principle. Achievement of the best effect is however according to the regularity and characteristics of sports technology teaching. In order to optimize the teaching effect, information is delivered in mainly five forms- text, images, animation, video and voice (explanation, music). The information is the main dynamic demonstration in this form having language interpretation as a complementary, through text, images, etc., are included in order to make the teaching effect optimization.

\subsection{Design of the Courseware Script}

Word copy is the courseware content in text form, which includes full courseware designed text content, and can also be written separately. Professionals write revision draft first, and send it to the relevant experts for review, modification of the opinions, and then according to different expert opinions, a symposium is held, modified, and finalized to the discussion, to ensure that the revision is scientific, accurate, and authentic for the script of the next card design. Courseware script cards are always making direct basis, playing a very important role. A good script card design in addition to the request that the writer should have certain experience in teaching, puts the teaching characteristics of psychology and computer into one, which further requires that the writers on one hand, understand the advantages and characteristics of the computer, to fully implement and complete the regular teaching method not difficult to complete tasks; On the other hand, it requires using objects and the psychology of courseware design being vivid conforming to the cognitive process of the students.

Script card design is mainly based on the text content of the courseware teaching thoughts, teaching strategies, teaching media choices and information presentation form designs. It includes the page text, images, graphics, images, sound, music and further specific content and its present form. The script cards ensure that the teaching content is accurate, complete and whether the teaching forms and media are in appropriate combination. Script card design is usually produced by course professionals and network multimedia experts. This is mainly to ensure that the multimedia professional staff clearly understands the course requirements.

\subsection{Courseware Making}

In order to strengthen interactive teaching and learning and using convenient courseware, usually super text, Hypertext links are adopted, which provide different buttons on each page. In the courseware, three kinds of commonly used words are present: ordinary static text, animated text and word of art. These three words are respectively produced by different software. Ordinary static text is mainly produced by direct text input system. Animated text increases with the 
user's appeal and artistic effect, and on one hand, it can be set with Authorware 5.0 character animation effects, and on the other hand, it is set for three-dimensional, color and special effects in dynamic change and adopts 3Dmaxstutio R3 and Cool 3 D3.0 in order to be prepared. Word of art is designed to make elegant, friendly interface, its production mainly composed of the function of Office 2000 to complete. In conclusion, the texts are made according to the different contents, different themes, adopt different forms, respectively.

Image mainly refers to the courseware interface using pictures, photos and graphics. This part mainly has three sources: the photos, the scanner images and generated image files. It makes use of Photoshop 5.0 and Impact balm for processing, or cutting or for repair or change. It is also used in some other software for downloading good images, graphics through the Print Screen. And after screening the picture on the clipboard, it is saved at standby after processing. Also, through Video Snip, some good video tapes are grabbed and then are applied to the courseware.

Animation production is the most difficult material production taking the longest time, especially, the human animation which is more time-consuming and laborious. This courseware, mainly adopts 3Dmaxstutio R3 in order to be made. As it is mainly prepared from different angles, it includes the full demonstration of high jump technology, high jump area, background, etc. The main point of this courseware is based on complete high jump technology, the brief illustration of the actions of popular athletes, teaching, and through which an idealized 3D model is abstracted. The whole process is divided into four steps: (1) a literal copy of technical essentials and excellent athletes on the basis of an ideal motion diagram, (2) entrance into 3Dmax interface, opening the material library, and extracting 3Dmax body materials. Because this material is often something rough with no color, therefore, this step is a key to modify, to make it look like an athlete, then similar clothes are provided to the same material, and assignment of the whole body on human skin color is completed; (3) the key step is the making process of the complete technology. This process takes almost hundreds of times of repeated revision. Starting from the athletes to rod, the running distance, direction, and the size of the stride, the swing arm, body introversion, the feet position by key frames of settings; such that the design keys of more than 120, 300 frames are rendered for this process; (4) the field and background design. In order to make the scene look more vivid, the site and background are designed in the high jump before complete technical production is conducted in a different file. The ground and the background are then built. Finally, the 3 files are merged on $3 \mathrm{dmax}$, constituting the same file, the modified and finalized version, and the spare one.

Courseware usually uses three kinds of voice including the record sound based on text revision, the interpretation of MIDI music as background, and the video footage of the acquisition card collection. It maintains the voice requirements for text reading at accurate, clear and reasonable pace. For the background music, MIDI chooses four combination highlights, i.e., the combined content of the interface, the color of the interface, the page of text voice, movement rhythm of courseware.

Video footage is one of the important content of sports technology courseware making. The main purpose of sports technology courseware is to help students establish correct, intuitive and clear demonstration of the action. In the process of making Video materials, audio-visual materials are selected through image acquisition card software and then are edited by the Video editor. In the collection, according to the different needs, different courseware are collected for sound, no sound, slow and often for several forms, such as quick acting group athletes. The text, images, video, animation, sound, video and other materials are included in the overall courseware. Courseware overall establishment is mainly based on multimedia courseware script cards and structure level. The production of courseware is mainly carried out through this Author ware. This part is not only a script card content, but also includes a variety of media information presented in the form of modification, background, music's re-election, size, color, font changes, etc. After overall production is through-out the page, with super text links to realize its strong interactivity, a threedimensional network structure is formed between each page (Fig. 3).

Courseware in total synthesis and preliminary revision is completed, to test whether the courseware apply or not by often conducting it in a teaching trial between students and teachers and after the trial, further changes are made based on the opinions of the teachers and students. It should be further revised according to the evaluation of the courseware, after fully considering the packaging, and burnt to the $\mathrm{CD}$, so that it can be run directly on the other computer.

\section{ANALYSIS AND DISCUSSION}

\subsection{Courseware Design Train of Thought}

This paper proposes a new multimedia network teaching pattern that highlights the initiative for the students in the process of teaching, to create a stimulating interest in students for learning, desire for knowledge, enabling the students to acquire knowledge of the environment according to their own personality, and obtain timely guidance and correction of their mistakes from electronic teachers at any time. In addition, the courseware will be used for sports technology teaching, and will be completed through the computer. Thereby, the optimization design gives full play of the teaching and the combination of computer software production advantages and considers the teachers' teaching and students learning processes. At the same time, it also directs guiding ideology of courseware script for writing.

Sports multimedia courseware in the process of design and production is mainly based on modern learning theory, education theory, system science theory, and modern teaching design theory, such as the direct psychological basis theory. Courseware is developed for the use of a certain object to be first determined in courseware design. Such as, high jump multimedia network courseware is developed mainly to be used as a professional network for sports in colleges and universities for teachers to borrow in the class teaching and as students' self-study tools. In addition, since it has 


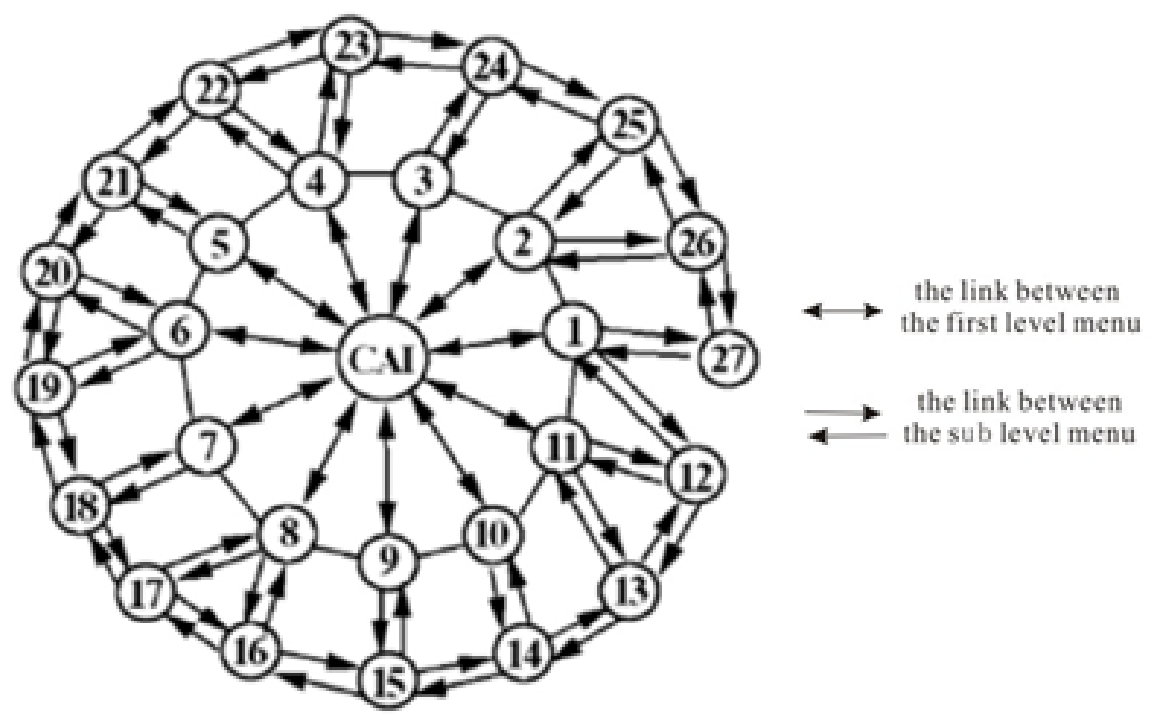

Fig. (3). The network structure diagram of courseware page link space.

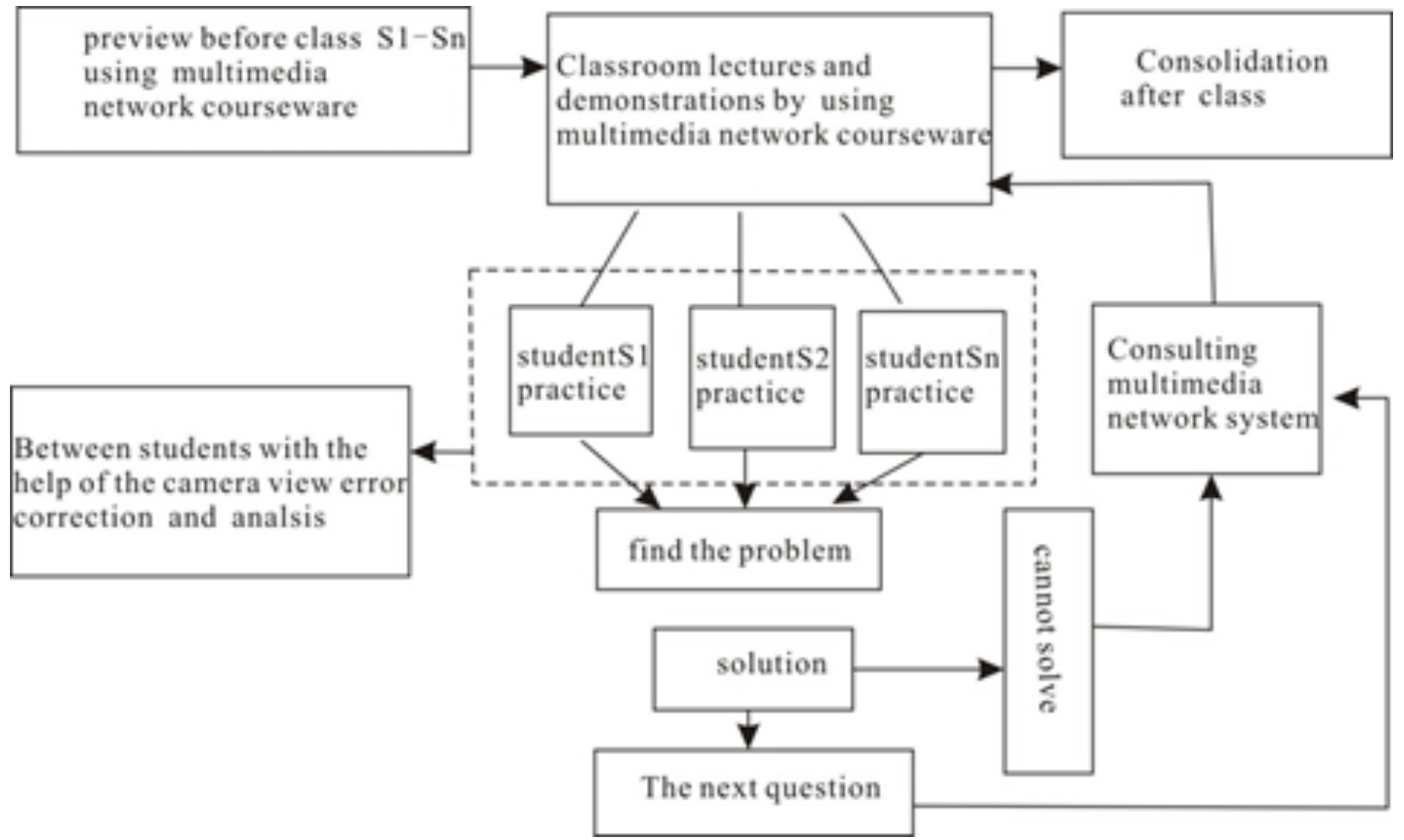

Fig. (4). Multimedia network education mode.

very good interactivity, it can also help in other relevant high jump teachings and trainings of electronic reference materials.

Courseware application in physical education teaching does not replace the teaching of teachers, but is a useful mean for the teacher in class; the teacher is still in a dominant position. Courseware developed once completed quickly lag behind the development of The Times, and specified in the courseware teaching contents, teaching methods and means are usually some universal problems and content, and often appear some special problems in the teaching, which requires experienced teachers solve these special problems, therefore, Teachers still play a leading role in the sports multimedia teaching rather than a coaching role.

\subsection{Basic Principle of Courseware Design}

The basic principle includes general principles such as controllability principle, the scientific principle, media selection and combination of optimization principle; friendly interface, and easy operation principle. Sports technology uses the superior multimedia teaching courseware, which is beneficial to difference teaching, according to their aptitude. It is conducive to good teaching experience cultivating students' intelligence factors and non-intelligence factors. Moreover, it is beneficial for teachers as it is energy saving and motivates them further. It further cultivates students' conscience for modern science and technology, promoting the foundations of creative thinking. 


\subsection{The Use Conditions and Methods of Multimedia Network Courseware}

The multimedia teaching classroom can undertake at least a 7-day class containing more than 486 computer drives, sound cards, having an external speaker, large screen color TV or a projector, in order to satisfy teachers' presentation on multimedia courseware. In order to make the most of multimedia courseware teaching, in addition to the above mentioned conditions, the classroom must also establish a local area network system, under the management of the server, with 30 or so computers, to satisfy 20 to 30 people at the same time for self-study or tutorial. To obtain the best condition, in addition to access to multimedia courseware in class, students in their spare time can also make use of multimedia courseware for preview or review consolidate, which requires students' dormitory equipped with computer or open multimedia classroom for students at any time of the day. With the development of science and technology level and the improvement of people's living standards, the computer prices are reducing rapidly, further providing a feasible technology condition for the sports multimedia teaching.

Having the basic hardware facilities, and software to keep up with in a timely manner, this network mainly requires two conditions: one is the basic requirement of teachers and students, as teachers and students should have basic computer knowledge and the knowledge of basic skills, such as modern media and the camera, for example, for broadcasting multimedia courseware and how to use camera and technical equipment, etc.; it is to have a good multimedia courseware, it is a "source" of the problem, if no good multimedia courseware, it is a good hardware can play a role.

In order to achieve good teaching effect, students are required to learn to preview before class and class after class to consolidate. Multimedia courseware for teaching must be adopted, but priority should be given to the three links in teaching (Fig. 4).

\section{CONCLUSION}

For optimizing the teaching design, courseware teaching goal and the content, design of the courseware text copy and scripts in the card is the key link in the process of making multimedia courseware. The text, images, animation, audio and video and other media material collection and skilled editor are the important premises of multimedia courseware. As the development and application of multimedia courseware in the high jump teaching provide the advanced visual teaching methods, these make up for the deficiency of the conventional teaching, and improve the students' participation and learning motivation. Furthermore, deepen students' understanding of knowledge, abstract to concrete, revealing the essence of the problem. Students can timely correct, review, strengthen and consolidate the knowledge, which is beneficial to optimize the teaching process. This helps in developing students' intelligence factors and non-intelligence factors, further helping students master the knowledge and cultivate their learning abilities.

For updating the standards of education, this teaching idea attaches great importance of the multimedia technology in education, which is significant for the teaching reform. In order to promote this in higher education, hardware construction of multimedia teaching should be strengthened, paying attention to cultivate the consciousness of teachers using the modern media, and by providing good learning opportunity for teachers. The competent departments should have the system and it should be recommended for the teachers to use multimedia courseware. Teachers themselves should have a sense of ugency, should take the initiative to accept new things, and apply it into teaching, and should also improve teaching efficiency and the quality of classroom. The student, in order to adapt to modern teaching and work in the future, on one hand, should have the basic knowledge of computers, should cooperate with the teacher, and on the other hand, should be capable of handling the modern tools and technology. True multimedia network teaching platform just not includes the data downloading, instead there is a strong functioning of multimedia teaching and real-time communication involving interactive learning function, which can achieve optimization of teaching resources. Multimedia network teaching platform in the teaching of sports promotion can be a complementary advantage to traditional teaching of college sports, improving the physical education teaching in colleges and universities, and providing students with the platform for autonomous learning and individualized learning.

\section{CONFLICT OF INTEREST}

The authors confirm that this article content has no conflict of interest.

\section{ACKNOWLEDGEMENTS}

This paper is supported by Philosophy and Social Science Research Program of Heilongjiang Province (No: 14D039)

\section{REFERENCES}

[1] Y. Wang, "Sports action using computer aided design feasibility study," Journal of Beijing sports university, vol.1, pp. 90-94, 2012.

[2] R. Qian, and X. Huang, "How to use the electronic technology teaching media," Journal Of Track And Field, vol.12, pp. 32-33, 1998.

[3] W. Yang, and Z. Feng, "For the development of gymnastics teaching CAI courseware of technology," Beijing: Beijing Sports Teachers College Journal, vol.1, pp. 62-69, 1999.

[4] X. Li, P. Ding, and L. Wen, "Multimedia teaching optimization design,” Guangzhou: Guangdong Higher Education Press, vol. 12, no. 2, pp. 101-115, 1996.

[5] Q. Bao, "World education development trend and the reform of Chinese education," Beijing: People's Education Press. Beijing: vol. 6, 1998.

[6] P. Yuan, "Multimedia courseware in physical education teaching theory research and exploration of the," Journal Of Business And The Development Of Science And Technology, vol. 15, no.12, pp. 101-115, 2011.

[7] F. Xiao, "Analyses the application of CAI in colleges and universities sports teaching," Journal of Luoyang Industrial College, no.4, 2013.

[8] M. Zhang, "Introduction to the application of modern information technology in the sports teaching," Journal Of New Technology And New Products In China, vol.7, pp. 101-114, 2009. 
[9] W. Fan, "Using electronic teaching continuously improve the quality of teaching," Changchun: China Commercial Press, 2009.

[10] Y. Si, "The problems and follow the principle of the computer aided teaching," Journal Of Anhui Education Scientific Research, vol. 6, no. 2, pp. 101-107, 2012.
[11] Q. Sun, "Bead effect of multimedia teaching in sports school," Journal of Sport, vol. 1, pp. 101-109, 2000.

Received: June 10, 2015

Revised: July 29, 2015

Accepted: August 15, 2015

(C) Qi and Zou; Licensee Bentham Open.

This is an open access article licensed under the terms of the (https://creativecommons.org/licenses/by/4.0/legalcode), which permits unrestricted, noncommercial use, distribution and reproduction in any medium, provided the work is properly cited. 